\title{
ASSESSMENT OF SEXUAL DIMORPHISM FROM THE MASTOID TRIANGLE USING 3D CT SCAN IN NEPALESE POPULATION
}

\author{
Pankaj Kumar Singh ${ }^{1^{*}}$, Raj Kumar Karki ${ }^{2}$, Abdul Sami Khan ${ }^{3}$, Dhiraj Kumar Shah ${ }^{4}$, Sushant Bhardwaj ${ }^{5}$
}

\section{Affiliation}

1. Assistant Professor, Department of Forensic Medicine, Kathmandu University School of Medical Sciences, Nepal

2. Associate Professor, Department of Forensic Medicine, Kathmandu University School of Medical Sciences, Nepal

3. Lecturer, Department of Forensic Medicine, Kathmandu University School of Medical Sciences, Nepal

4. 2nd year Resident, Department of Forensic Medicine, Kathmandu University School of Medical Sciences, Nepal

5. Medical Officer, Department of Emergency, Kathmandu University School of Medical Sciences, Nepal

\section{ARTICLE INFO}

Received : 09 March, 2021
Accepted : 25 August, 2021
Published : 04 November 2021

(C) Authors retain copyright and grant the journal right of first publication with the work simultaneously licensed under Creative Commons Attribution License CC - BY 4.0 that allows others to share the work with an acknowledgment of the work's authorship and initial publication in this journal.

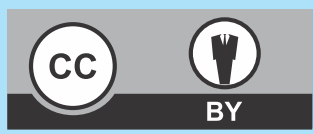

ORA 256

DOI: https://doi.org/10.3126/bjhs.v6i2.40330

* Corresponding Author

Dr. Pankaj Kumar Singh

Assistant Professor

Department of Forensic Medicine

Kathmandu University School of Medical Sciences, Nepal Email:drpankaj_s@yahoo.co.in

ORCID: https://orcid.org/0000-0002-6681-9532

\section{Citation}

Pankaj Kumar Singh, Raj Kumar Karki, Abdul Sami Khan, Dhiraj Kumar Shah, Sushant Bhardwaj. Assessment of Sexual Dimorphism from the Mastoid Triangle Using 3D CT Scan in Nepalese Population. BJHS 2021;6(2)15. 1486-1491.

\section{ABSTRACT}

\section{Introduction}

Skull plays an important role, second only next to pelvis for sex determination. In skull, mastoid and occipital region due to its anatomical location is the most protected region, offering high resistance to decomposition and any form of tempering. With the intension of studying sexual dimorphism in the mastoid region involving mastoid process, we initiated this study. The technique we adopted was first introduced by Paiva and Segre, i.e. measuring the distance between three cranio-metric land mark (Porion, Mastoidale, and Asterion) and calculating the area of the triangle to study sexual dimorphism.

\section{Objective}

The objective of this study is to determine sex based on mastoid triangle dimensions measured in 3D reconstructed computed tomography of the skull.

\section{Methodology}

The study included 196, 3D reconstructed CT scan images of skull, 98 of which were males and 98 of which were females. "The three craniometric points were marked to demarcate the mastoid triangle on both side". Heron's formula was used for measurement of mastoid triangle areas.

\section{Result}

Descriptive statistics and the student t-test revealed that males have larger mastoid triangle dimensions in all measurements than females, with a significant difference $(p<0.000)$ between them. The paired t-test revealed no statistically significant difference $(p<0.05)$ between the right and left sides. Apart from angle asterion $(p<0.05)$ on the right side, no other mastoid triangle angles on either side showed a significant difference. The predictability of mastoid triangle measurements and areas was determined using a discriminant function and ROC curve analysis. The calculated mastoid triangle measurements and areas were $72.5 \%$ of Asterion to Porion, $74.5 \%$ of Asterion to Mastoidale, $86.3 \%$ of Mastoidale to Porion, and $88.2 \%$ of areas, respectively.

\section{Conclusion}

The study findings suggest that mastoid triangle could be used to determine gender in the case of fragmentary skull remains by the forensic experts in the course of investigation. In order to generalize the data nationally, an autopsy-based,large sample size study on different age groups should be conducted.

\section{KEYWORDS}

Autopsy, Computed Tomography, Forensic Anthropology, Mastoid process, Mastoid Triangle. 


\section{INTRODUCTION}

Individual identification is of prime importance in mass disasters, road traffic accidents, fire accidents and in criminal cases, where there is intentional dismembering and mutilation of the body. ${ }^{1}$ Civilized societies recognize the need for identity in living as well as in death. Identity of a person means individuality of that person. ${ }^{2}$ The main objective of autopsy is identification. Unknown bodies in full or in parts and at times skeletal remains are brought for examination at mortuary. Anthropological or biological identification helps us in identification by excluding the given population and also in cases where DNA and figure print cannot be obtained. Alphonso Bertilion (1853 - 1914) created the first anthropometric scientific system based on physical measurements for identifying criminals in $1880 .^{3}$

Forensic identification has evolved into an art of science which involves various specialities. ${ }^{3}$ Forensic anthropology is one such sub-specialty within Forensic Science, which deals with human skeletonised remains and their environment. ${ }^{4}$ In the field of Forensic anthropology determining sex from skeletal remains, especially from isolated bones, has been an age old problem. When it comes to skeletal sex determination, metric analysis are often found to be of superior value as they are more objective but also provide greater statistical weight than non-metric traits. ${ }^{5}$ Skull plays an important role in sex determination, being the second best region for sex determination only next to pelvis. ${ }^{4}$ In skull the regions that have been studied for sexual dimorphism are teeth, ${ }^{6}$ nasal bone, ${ }^{7}$ frontal bone, ${ }^{8}$ occipital bone, ${ }^{9}$ foramen magnum ${ }^{10}$ and palate. ${ }^{11}$ However, mastoid and occipital region due to its anatomical location is the most protected region, offering high resistance to decomposition and any form of tempering.

With the intension of studying sexual dimorphism in the mastoid region involving mastoid process, we initiated this study. The technique we adopted was first introduced by Paiva and Segre, i.e. measuring the distance between three cranio-metric land mark (Porion, Mastoidale, and Asterion) and calculating the area of the triangle to study sexual dimorphism. ${ }^{12}$ However we have added other dimension to the study carried out by Paiva and Segre, ${ }^{12}$ i.e. the angles of the mastoid triangle. Anthropological studies are subjected to intra-population and inter-population variation; in addition recent studies in the field of neurosurgery have questioned the reliability of asterion as a stationary land mark, ${ }^{13,14}$ thus providing the ground for our study in Nepalese population.

\section{METHODOLOGY}

The study is a hospital-based cross-sectional study conducted in Forensic Medicine department in collaboration with Department of Radio-diagnosis of Kathmandu University School of Medical Sciences for three month period, from December 2020 to February 2021. The sample size was determined using the Cochran equation $\left(n_{0}=Z^{2} \sigma^{2} / e^{2}\right)$. A total of 196 head CT scan images of adult males and females over the age of 20 years were studied. Individuals who required CT head for diagnostic purposes were randomly selected for this study. The exclusion criteria for this study were as follows:
- Age less than 20 years,

- Skull fractures involving the mastoid region

- Pathology involving the mastoid region was not included in our study.

Institutional Review Committee of Kathmandu University School of Medical Sciences(IRC-KUSMS Approval number: 02/21), an approval was obtained in accordance with Declaration of Helsinki, in advance to initiating this study. Paiva and Sergre ${ }^{12}$ had defined the anatomical landmarks of Mastoid Triangle, which became the base for this study and the landmarks were identified and marked on both side (right and left) of cranium, which are as following:

a) Asterion (As): Meeting point of lambdoid, occipitomastoid and parietomastoidstures.

b) Mastoidale (Ms): Lowest craniometric point at the mastoid process.

c) Porion (Po): Highest point on the surface of the external auditory meatus.

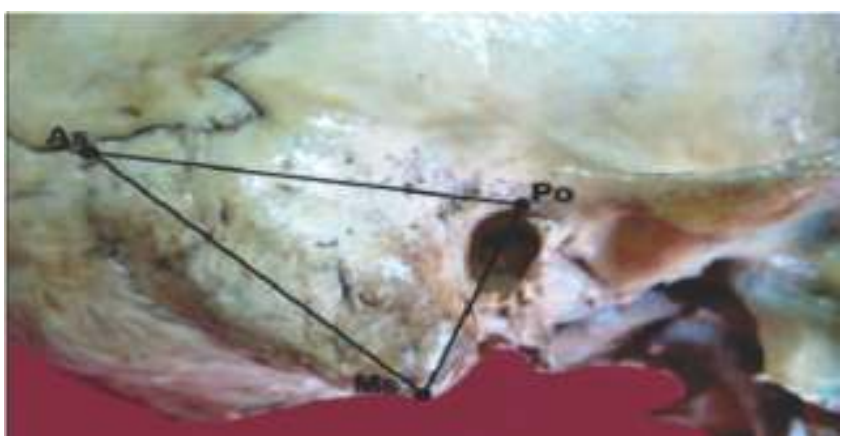

Figure 1: Anatomical landmarks of Mastoid Triangle.

The line joining these above mentioned points forms the "Mastoid Triangle". The distance between these point on both sides were measured directly on the DICOM images using inbuilt Electronic Caliper in DICOM viewer software in centimetres.

AP (Asterion to Porion): Distance between asterion to porion. For right side the word " $R$ ", and " $L$ " for left was used. MP (Mastoidale to Porion): Distance between mastoidale to porion. For right side the word " $\mathrm{R}$ ", and " $\mathrm{L}$ " for left was used.

AM (Asterion to Mastoidale): Distance between asterion to mastoidale. For right side the word " $R$ ", and "L" for left was used.

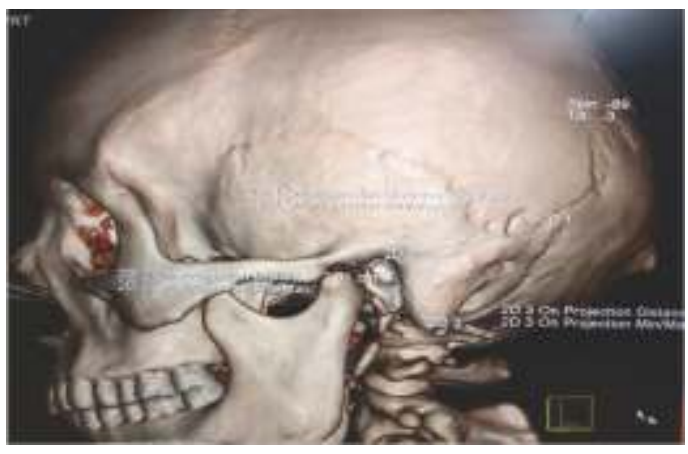

Figure 2: Measurements of Mastoid Triangle on 3D-CT of Head. 
Area of the both sides of mastoid triangle was calculated using Heron's formula in centimetre square $\left(\mathrm{cm}^{2}\right)$ as done by Kemkes and Gobel. ${ }^{15}$ The angles of the mastoid triangle were calculated using online software Solve triangle as used earlier by Kanchan et al. ${ }^{16}$ in which the lengths between the landmarks, asterion, porion, and mastoidale, were fed in and the angle calculated and displayed. These are documented as follows:

- AngA (Angle Asterion): The angle between AM and AP. For right side the word " $\mathrm{R}$ ", and " $\mathrm{L}$ " for left was used.

AngP (Angle Porion): The angle between AP and MP. For right side the word " $\mathrm{R}$ ", and " $\mathrm{L}$ " for left was used.

AngM (Angle Mastoidale): The angle between MP and AM. For right side the word " $\mathrm{R}$ ", and " $\mathrm{L}$ " for left was used.

Volumetric Head CT scans was done on 128 slices Simen Somatom Perspective Scanner at $5 \mathrm{~mm}$ thickness with $5 \mathrm{~mm}$ interval, the reconstruction was done at $1 \mathrm{~mm}$ thickness and the measurements were measured on multi-planner scan of saggital view.

\section{Analysis}

The data thus collected were entered in Microsoft Word in the initial stage, which was later analysed using IBM SPSS (Statistical Package for Social Sciences) version 21 software. Descriptive analysis was done for age and the measurements taken following with the Paired t-test done to compare right and left side of the cranium. Then Student t-test was done to equate between the sexes i.e. male and female. The level of significance is set at $p$-value $<0.05$. Discriminant Function Analysis (DFA) and Receiver Operating Characteristics (ROC) were also done.

\section{RESULTS}

Out of a total 196 individual head CT scans 98 were of males and 98 were of females. The age ranged from 20 to 89 years for males and 21 to 86 years for females, with a mean age of $44.56(S D \pm 17.83)$ years for males and $45.26(S D \pm 18.51)$ years for females (Table 1).

\begin{tabular}{lccccc}
\multicolumn{6}{l}{ Table 1: Descriptive statistics of age distribution. } \\
Sex & $N$ & Minimum & Maximum & Mean & SD \\
Males & 98 & 20 & 89 & 44.56 & 17.83 \\
Females & 98 & 21 & 86 & 45.26 & 18.51
\end{tabular}

\section{SD: Standard Deviation}

Tables 2 shows descriptive statistics and a student t-test, demonstrating that males have larger mastoid triangle dimensions in all measurements and calculations. The student t-test, showed that there was a significant $(p<0.000)$ difference between males and females in all of the measurements and calculated areas. The right and left sides of the mastoid triangle were compared using a paired t-test, which revealed no significant differences $(p<0.05)$. However, with the exception of angle asterion $(p<0.01)$ on the right side, all of the angles of the mastoid triangle on both sides, i.e. right and left, showed no significant difference ( $p>0.05)$, as shown in table 3.
Table 2: Descriptive statistics and student t-test of the mastoid triangleas per sex

$\begin{array}{lllllllll}\text { Sex Statistics } & R A P & R A M & R M P & R A r e a & L A P & \text { LAM } & \text { LMP } & \text { LArea } \\ \text { Male } & & & & & & & & \\ \text { Mean } \pm S D & 4.85 \pm 0.45 & 4.96 \pm 0.49 & 3.17 \pm 0.37 & 7.26 \pm 1.05 & 4.87 \pm 0.44 & 5.04 \pm 0.48 & 3.08 \pm 0.29 & 7.22 \pm 0.89 \\ \text { Median } & 4.86 & 5.01 & 3.18 & 7.18 & 4.91 & 5.11 & 3.05 & 7.21 \\ \text { Minimum } & 3.46 & 3.65 & 2.17 & 4.66 & 3.58 & 3.69 & 2.43 & 4.77 \\ \text { Maximum } & 6.22 & 6.63 & 4.92 & 10.11 & 5.89 & 6.00 & 3.92 & 9.13 \\ \text { Female } & & & & & & & & \\ \text { Mean } \pm S D & 4.39 \pm 0.45 & 4.56 \pm 0.46 & 2.70 \pm 0.28 & 5.68 \pm 0.86 & 4.38 \pm 0.43 & 4.55 \pm 0.48 & 2.71 \pm 0.27 & 5.74 \pm 0.91 \\ \text { Median } & 4.46 & 4.59 & 2.68 & 5.66 & 4.35 & 4.54 & 2.68 & 5.70 \\ \text { Minimum } & 2.91 & 3.29 & 1.93 & 3.85 & 2.92 & 3.48 & 2.18 & 3.83 \\ \text { Maximum } & 5.23 & 5.53 & 3.52 & 8.03 & 5.46 & 5.82 & 3.47 & 8.42 \\ \text { t test } & 6.991 & 5.829 & 9.962 & 11.465 & 7.796 & 7.143 & 9.103 & 11.504 \\ p \text {-value } & 0.000 & 0.000 & 0.000 & 0.000 & 0.000 & 0.000 & 0.000 & 0.000\end{array}$

SD: Standard Deviation.

Mastoid triangle of both right and left side has shown sexual dimorphism evidently from student t-test therefore the data was further analysed using Discriminant Function Analysis for individual parameters, areas calculated and then all the parameters combined. Receiver Operating Characteristic was done for all the measurements taken and areas calculated.

\begin{tabular}{|c|c|c|c|c|c|c|}
\hline Sex Statistics & RAngA & RAngP & RAngM & LAangA & LAangP & LAngM \\
\hline \multicolumn{7}{|l|}{ Male } \\
\hline Mean $\pm S D$ & $37.60 \pm 5.68$ & $73.31 \pm 7.89$ & $69.05 \pm 6.95$ & $37.69 \pm 8.09$ & $74.31 \pm 6.83$ & $67.98 \pm 8.40$ \\
\hline Median & 37.45 & 73.09 & 70.02 & 35.53 & 73.89 & 69.86 \\
\hline Minimum & 24.91 & 39.35 & 49.18 & 28.38 & 54.96 & 29.66 \\
\hline Maximum & 58.72 & 91.58 & 88.69 & 79.46 & 94.03 & 8618 \\
\hline \multicolumn{7}{|l|}{ Female } \\
\hline Mean $\pm S D$ & $34.91 \pm 4.94$ & $75.66 \pm 8.34$ & $69.41 \pm 8.85$ & $35.83 \pm 6.14$ & $75.73 \pm 6.65$ & $68.79 \pm 6.74$ \\
\hline Median & 34.37 & 75.90 & 70.27 & 34.87 & 75.45 & 69.08 \\
\hline Minimum & 24.52 & 52.57 & 43.21 & 26.23 & 61.01 & 53.74 \\
\hline Maximum & 52.67 & 97.87 & 96.94 & 72.55 & 92.48 & 84.04 \\
\hline$t$ test & 3.536 & -2.027 & -0.317 & 1.811 & -1.480 & -0.742 \\
\hline$p$-value & 0.001 & 0.44 & 0.752 & 0.072 & 0.140 & 0.454 \\
\hline
\end{tabular}

SD: Standard Deviation.

Discriminant function analysis of all the measurements taken and areas calculated showed a significant difference $(p>0.000)$ as detailed in table 4 . Similar results were also abserved when all the parameters were combined and subjected to discriminant function analysis detailed in table 5 .

\begin{tabular}{|c|c|c|c|c|}
\hline & RAP \& LAP & RAM \& LAM & $R M P \&$ LMP & $R$ Area \& LArea \\
\hline Eigen value & 0.363 & 0.280 & 0.593 & 0.833 \\
\hline Canonical correlation & 0.516 & 0.468 & 0.610 & 0.674 \\
\hline Wilks Lambda & 0.733 & 0.781 & 0.628 & 0.545 \\
\hline Chi-square & 59.824 & 47.601 & 89.890 & 116.970 \\
\hline Significance & 0.000 & 0.000 & 0.000 & 0.000 \\
\hline Structure matrix & $\begin{array}{l}R=0.833 \\
L=0.929\end{array}$ & $\begin{array}{l}R=0.791 \\
L=0.970\end{array}$ & $\begin{array}{l}R=0.929 \\
L=0.849\end{array}$ & $\begin{array}{l}R=0.902 \\
L=0.905\end{array}$ \\
\hline $\begin{array}{l}\text { Unstandardized } \\
\text { Canonical Discriminant } \\
\text { Function Coefficients }\end{array}$ & $\begin{array}{l}R=0.990 \\
L=1.521 \\
C=-11.618\end{array}$ & $\begin{array}{l}R=0.645 \\
L=1.604 \\
C=-10.769\end{array}$ & $\begin{array}{l}R=1.958 \\
L=1.618 \\
C=-10.454\end{array}$ & $\begin{array}{l}R=0.570 \\
L=0.617 \\
C=-7.692\end{array}$ \\
\hline Group Centroid & $\begin{array}{l}\text { Male }=0.600 \\
\text { Female }=-0.600\end{array}$ & $\begin{array}{l}\text { Male }=0.526 \\
\text { Female }=-0.526\end{array}$ & $\begin{array}{l}\text { Male }=0.766 \\
\text { Female }=-0.766\end{array}$ & $\begin{array}{l}\text { Male }=0.908 \\
\text { Female }=-0.908\end{array}$ \\
\hline
\end{tabular}

\section{R:Right; L:Left; C:Constant.}

Table 5: Discriminant Function Analysis of all the parameters of Mastoid triangle of Right \&Left sides.

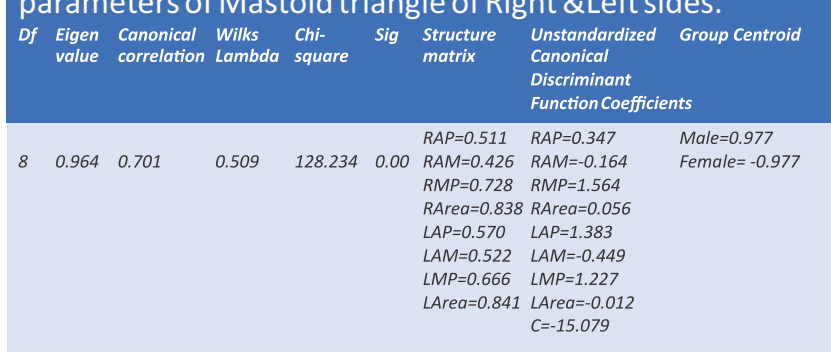

C: Constant 
The predictability for each of the measurements and areas calculated of mastoid triangle were $73.0 \%$ of Asterion to Porion, $70.9 \%$ of Asterion to Mastoidale, $84.2 \%$ of Mastoidale to Porion, and $81.1 \%$ of areas respectively. When all the parameters were combined the predictability increased to $85.7 \%$, as demonstrated in table 6 .

$\begin{aligned} & \text { Table 6: Predictability of sex in the sample collected. } \\ & \text { RAP \& LAP }\end{aligned}$
$\begin{aligned} & \text { RAM \& } \\ & \text { LAM }\end{aligned}$

The ROC curve for all the parameters and the areas calculated of mastoid triangle for males are shown in figure 1 , which showed significance in all the parameters. The highest area under the curve in males was seen in Right Area (RArea) 0.881 with standard error 0.025 , followed by Left Area (LArea:0.877; standard error:0.024); Right Mastoidale to Porion (RMP:0.856; standard error 0.029); and Left Mastoidale to Porion (LMP: 0.825; standard error 0.030). The highest area under the curve in females was seen in Right Asterionto Mastoidale(RAM) 0.281 with standard error 0.036, followed by Left Asterion to Mastoidale (LAM:0.235; standard error:0.034); Right Asterion to Porion (RAP:0.219; standard error 0.033); and Left Asterion to Porion (LAP: 0.214; standard error 0.033)respectively detailed in table 7.

\begin{tabular}{|c|c|c|c|c|}
\hline \multirow[t]{2}{*}{ Variables } & \multicolumn{2}{|c|}{ Area } & \multirow[t]{2}{*}{ SE } & \multirow[t]{2}{*}{ Significant } \\
\hline & Males & Females & & \\
\hline$R A P$ & 0.781 & 0.219 & 0.033 & 0.000 \\
\hline RAM & 0.719 & 0.281 & 0.036 & 0.000 \\
\hline$R M P$ & 0.856 & 0.144 & 0.029 & 0.000 \\
\hline RArea & 0.881 & 0.119 & 0.025 & 0.000 \\
\hline LAP & 0.786 & 0.214 & 0.033 & 0.000 \\
\hline LAM & 0.765 & 0.235 & 0.034 & 0.000 \\
\hline$L M P$ & 0.825 & 0.175 & 0.030 & 0.000 \\
\hline LArea & 0.877 & 0.123 & 0.024 & 0.000 \\
\hline
\end{tabular}

\section{SE: standerd Error}

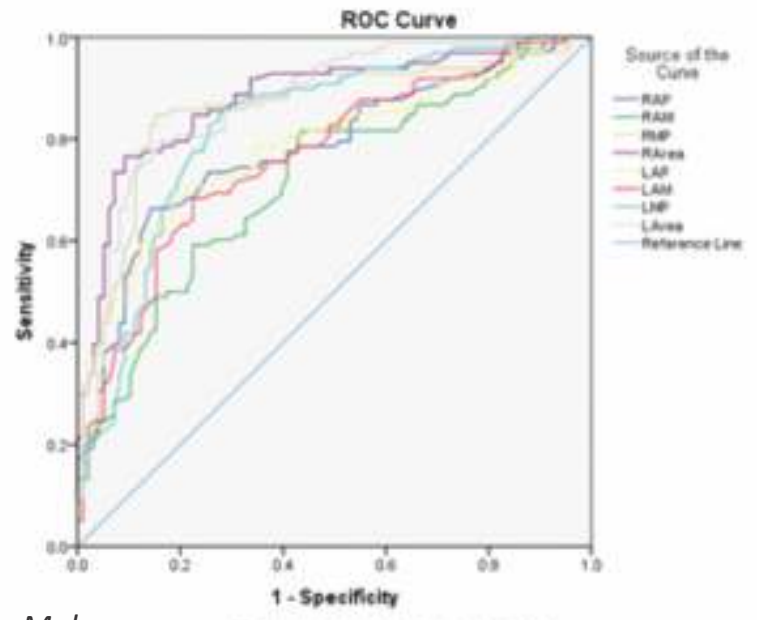

Males

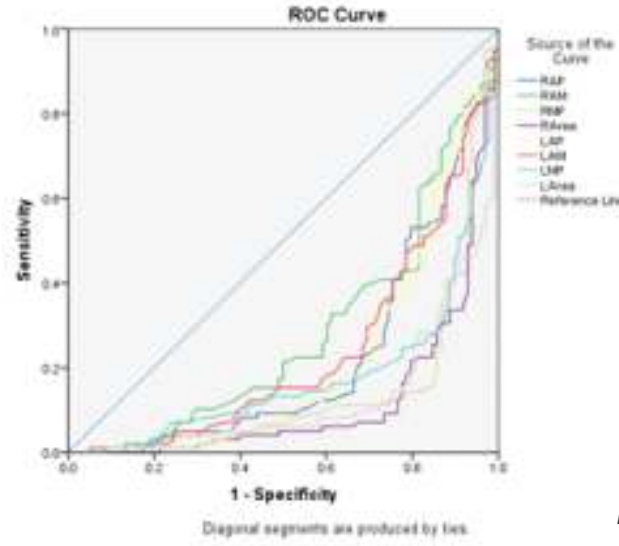

Females

Figure 3: ROC curve of all the parameters taken and calculated in males and females.

Table 8: Measurements of mastoid triangle and area calculated on right side in our study $(\mathrm{cm})$ and previous studies $(\mathrm{mm})$.

\begin{tabular}{|c|c|c|c|c|c|c|c|c|c|}
\hline \multirow[t]{2}{*}{ Study } & \multirow[t]{2}{*}{ Population } & \multicolumn{2}{|c|}{ Po Ma } & \multicolumn{2}{|c|}{ As $\mathrm{Ma}$} & \multicolumn{2}{|l|}{ Po As } & \multicolumn{2}{|c|}{ Area } \\
\hline & & $M$ & $\boldsymbol{F}$ & $M$ & $\boldsymbol{F}$ & $M$ & $\boldsymbol{F}$ & $M$ & $\boldsymbol{F}$ \\
\hline Paiva\& Segre & Brazil & - & & - & - & - & - & 7.52 .1 & 608.7 \\
\hline Kemkes\& Globel ${ }^{15}$ & German & 30.9 & 28.9 & 50.5 & 49.4 & 48.6 & 46.3 & 717.6 & 655.9 \\
\hline & Portuguese & 31.5 & 28.4 & 49.5 & 45.4 & 47.7 & 45.1 & 718.9 & 609.5 \\
\hline Galdames et al. ${ }^{16}$ & Brazil & 30.7 & 27.6 & 50.2 & 48.3 & 47.5 & 46.7 & 703.3 & 624.1 \\
\hline Manoonpol etal. ${ }^{19}$ & Thailand & 35.1 & 31.2 & 57.2 & 52.2 & 53.5 & 49.6 & 912.7 & 725.5 \\
\hline Singh et al. ${ }^{17}$ & North India & 23.1 & 21.7 & 45.2 & 41.1 & 41.9 & 39.0 & 478.0 & 412.1 \\
\hline Kanchan et al. ${ }^{18}$ & South India & 27.4 & 25.7 & 48.7 & 47.2 & 43.9 & 42.3 & 592.2 & 542.1 \\
\hline Present study $(\mathrm{cm})$ & Nepal & 3.17 & 2.70 & 4.96 & 4.56 & 4.85 & 4.39 & 7.26 & 5.68 \\
\hline
\end{tabular}

\section{DISCUSSION}

The skull is an important structural component in determination of sex. There are two methods for determining sex from skull measurements: morphological and morphometric. Morphometric method is more valued than morphological method as it has high statistical weight age and is more objective than morphological method. ${ }^{15}$ Researchers have been drawn to mastoid region for sex determination for long period. Krogman used the size of mastoid process as one of his traits for sex estimation. ${ }^{4}$ Similarly many studies have focused on mastoid process for sex determination. But recent studies conducted by the neurosurgery has suggested Asterion not being a stationary point, ${ }^{13,14}$ which implies that Asterion is subjected to inter and intra population variation. So, as Paiva and Segre suggested, this study was conducted to determine sex from mastoid triangle measurements as it is first of its kind, in Nepalese population.

The present study has demonstrated males have larger mastoid triangle than its counterpart and there is a statistical significant difference $(p<0.000)$ between them. However, there was no significant difference when right and left sides were compared. The predictability for sex estimation was higher than in any previous study, at $73.0 \%$ when asterion to porion of both sides was used, $70.9 \%$ when asterion to mastoidale was used, $84.2 \%$ when mastoidale to porion was used, and $81.1 \%$ when areas were used. When all measurements and areas calculated were obtained, the predictability increased to $95.7 \%$. The ROC curve further indicated the specificity and sensitivity of the various 
measurements and areas calculated in the mastoid triangle. A total of six studies have been carried out, in which mastoid triangle was focus of study for determination of sex. Paiva and Segre were the first and also introduced this technique, and they studied on Xerographic of the mastoid region. ${ }^{12}$ Our study showed the same results as that of Paiva and Segre, ${ }^{12}$ i.e. males have larger mastoid triangle and there was significant difference between male and female. The studies that were conducted after Paiva and Segre were done on dry skulls or at autopsy as suggested by Paiva and Segre, but our study was conducted in 3D-CT head. Similar results were also documented by other researchers in different population, except for study conducted by Galdames et al., where in the area of mastoid triangle of right side had significant difference. ${ }^{17}$ (Table 8)

Our study demonstrated that the different measurements of mastoid triangle and the areas calculated were higher than the study conducted by Singh et al. ${ }^{17}$ and Kanchan et al. ${ }^{16}$ in Indian population, however it was in close proximity to the studies conducted by Paiva et al. ${ }^{12}$ in Brazilian population, Kemkes et al. ${ }^{15}$ in German and Portuguese population, and Galdames et al. ${ }^{18}$ in Brazilian population. The highest measurements of mastoid triangle were noted in Thai population conducted by Manoonpolet al. ${ }^{19}$ Nevertheless, the predictability of sex was higher in our study in comparison to all the six studies conducted in different population.

Therefore, our study confirms that estimating sex in adult human skulls is based on males' larger size and robustness in comparison to females, which is attributed to the rate of skull growth, as male skulls experience growth even before puberty, which females do not. Features whose development is related to major muscle attachments and their action have been reported to be better indicators of sex. This may be the reasons for sexual dimorphism observed in the mastoid triangle in our and other studies in different populations. The disparity in measurements and areas calculated in our study versus other studies could be attributed to interpopulation differences. Therefore, our study confirms that estimating sex in adult human skulls is based on males' larger size and robustness in comparison to females, which is attributed to the rate of skull growth, as male skulls experience growth even before puberty, which females do not. Features whose development is related to major muscle attachments and their action have been reported to be better indicators of sex. This may be the reasons for sexual dimorphism observed in the mastoid triangle in our and other studies in different populations. The disparity in measurements and areas calculated in our study versus other studies could be attributed to inter-population differences.

\section{CONCLUSION}

The study findings suggest that mastoid triangle could be used to determine gender in the case of fragmentary skull remains by the forensic experts in the course of investigation. However, further research with a larger sample size is needed to emphasize the aforementioned points.

\section{LIMITATIONS OF THE STUDY}

Though our study demonstrates mastoid triangle as a good indicator for sex determination, the sample size may be limitation of our study. In order to generalize the data nationally, an autopsy-based,large sample size study on different age groups should be conducted.

\section{ACKNOWLEDGEMENTS}

We would like to acknowledge the Department of Radiodiagnosis of Kathmandu University School of Medical Sciences for their support in collection of data and also the Department of Forensic Medicine for their continuous support.

\section{CONFLICT OF INTEREST}

The authors have no conflict of interest to declare.

\section{FINANCIAL DISCLOSURE}

No support in the form of grants.

\section{REFERENCES}

1. Burns KR. Forensic anthropology training manual. 2nd ed. Upper Saddle River: New Jersey Prentice-hall; 2007.

2) Mukherjee JB. Personal Identification. In: Forensic Medicine and Toxicology. 2nded. New Delhi: Arnold Associates, 1994: 72, 128-129.

3) Knight B. Identification. The establishment of identity of human remains. In: Knight's Forensic Pathology. 3rd ed. London: Arnold, 2004: 98-135.

4) Krogman WM, Iscan MY. Skeletal Age: Cranium, Skeletal Age: Post Cranium and Determination of Sex and Parturition. In: Human Skeleton in Forensic Medicine. 2nd ed. USA: Charles C Thomas Publishers 1986: 103-267, 153-187.

5) France DL. Observational and Metric Analysis of Sex in the Skeleton. In: Reichs KJ, Editor. Forensic Osteology. Advances in the Identification of Human Remains. Springfield: Charles C Thomas, 1986: 163-86.
6) MacalusoJr PJ. Investigation on the utility of Permanent Maxillary Molar Cusp areas for sex estimation. Forensic Sci Med Pathol 2011; 7:233-47.https://doi.org/10.1007/s12024-010-9204-7.

7) Schiwy-Bochat $\mathrm{KH}$. The roughness of supra Nasal Region- A morphological sex trait. Forensic Scilnt 2001; 177(1-2): 713.https://doi.org/10.1016/s0379-0738(00)00434-5

8) May H, Peled N, Dar G, Cohen H, Abbas J,Madlej B, H Israel. Hyperostosis frontalisinterna: criteria for sexing and aging a skeleton. Int J Legal Med 2011; 125:669-73.https://doi.org/10.1007/s00414010-0497-6

9) L FrancesquiniJúnior 1, M A Francesquini, B M De La Cruz, S D R Pereira, G M B Ambrosano, C M R Barbosa, E DarugeJúnior, A A Del BelCury, E Daruge. Identification of sex using cranial base measurements. J Forensic Odontostomatol 2011; 25: 7-11.PMID: 17577972. 
10) Singh PK, Tamrakar D, Karki S, Menezes RG. Determination of Sex from the Foramen Magnum using 3DCT: A Nepalese Study. Kathmandu Univ Med J 2017;57(1):61-5.PMID: 29446365.

11) Burris BG, Harris EF. Identifiication of race and sex from palate dimensions. J Forensic Sci 1998; 43: 989-63.PMID: 9729811.

12) Paiva LAS, Sergre M. Sexing the human skull through mastoid process. Rev HospClin Med Sao Paulo 2003; 58: 15-20.https:// doi.org/10.1590/50041-87812003000100004

13) Day JD, Tschabitscher M. Anatomic position of the asterion. Neurosurgery 1998; 42: 198-9.https://doi.org/10.1097/00006123199801000-00045

14) Sripairojkul B, Adultrakoon A. Anatomic position of the asterion and its underlying structure. J Med Assoc Thai 2000; 83: 1112-5.PMID: 11075981

15) Kemkes A, Gobel T. Metric assessment of the "mastoid triangle" for sex determination: a validation study. J Forensic Sci 2006; 51: 9859.https://www.researchgate.net/deref/http\%3A\%2F\%2Fdx.doi.org \%2F10.22159\%2Fajpcr.2018.v11i7.25986

16) Kanchan T, Gupta A, Krishan K. Estimation of sex from mastoid triangle - A craniometric analysis. J Forensic Leg Med 2013; 20: 85560.https://doi.org/10.1016/j.jflm.2013.06.016
17) Singh RP, VermaSK,Tyagi AK. Determination of sex by measurements of area of mastoid triangle in human skull. Indian J Forensic Med Toxicol 2008; 6: 29-43.In:Kanchan T, Gupta A, Krishan K. Estimation of sex from mastoid triangle - A craniometric analysis. J Forensic Leg Med 2013; 20: 855-60.https://doi.org/10.1016/j.jflm.2013.06.016

18) Galdames ICS, Matamala DAZ, Smith RL. Sex determination using mastoid process measurements in Brazilian skulls. Int J Morphol 2008;26:941-4.http://dx.doi.org/10.4067/S0717-95022008000400025

19) Manoonpol C, Plakornkul V. Sex determination using mastoid process measurements in Thais. J Med Assoc Thai 2012; 95: 42339.PMID: 22550843

20) Baughan B, Demirjian A. Sexual dimorphism is the growth of the cranium. Am J PhysAnthropol 1987;49: 383-90.https://doi.org/ 10.1002/ajpa.1330490311

21) Franklin D, Freedman L, Milne N, Oxnard CE. A geometric morphometric study of sexual dimorphism in the crania of indigenous southern Africans. S Afr J Sci 2006; 102: 229-43.https://doi.org/ 10.1002/ ajhb.20569 